\title{
Presyncope in a Patient Status Post Pectus Excavatum Repair
}

\author{
Mikhail Carlow' \\ Rajeev Seecheran ${ }^{2}$ \\ Valmiki Seecheran $\mathbb{D}^{2}$ \\ Sangeeta Persad (D) ${ }^{2}$ \\ Stanley Giddings (iD) ${ }^{3}$ \\ Sadi Raza ${ }^{4}$ \\ Taarik Dookie' \\ Naveen Seecheran (iD) \\ 'Cardiology Unit, Advanced \\ Cardiovascular Institute, Port of Spain, \\ Trinidad and Tobago; ${ }^{2}$ Department of \\ Medicine, North Central Regional Health \\ Authority, Mt. Hope, Trinidad and \\ Tobago; ${ }^{3}$ Department of Clinical Medical \\ Sciences, University of the West Indies, \\ St. Augustine, Trinidad and Tobago; \\ ${ }^{4}$ Department of Cardiovascular Services, \\ HeartPlace Dallas, Dallas, TX, USA
}

Correspondence: Naveen Seecheran Department of Clinical Medical Sciences, University of the West Indies, 2nd Floor, Building \#67, Eric Williams Medical Sciences Complex, Mt. Hope, Trinidad, St. Augustine, WI, Trinidad and Tobago

$\mathrm{Tel}+$ I 868 663-4332

Email nseecheran@gmail.com

\begin{abstract}
Pectus excavatum (PEX) is an anterior chest wall deformity with sternal depression relative to the costal cartilages. We describe a patient status post remote PEX repair who presented with presyncope attributed to bifascicular block, partial right ventricular outflow tract (RVOT) obstruction, and right coronary artery (RCA) ischemia. Key Clinical Message: The clinician should be cognizant of the hemodynamic impact and electrocardiographic changes in a symptomatic patient status post pectus excavatum repair.
\end{abstract}

Keywords: presyncope, pectus excavatum

\section{Introduction}

Pectus excavatum (PEX) is an anterior chest wall deformity with sternal depression relative to the costal cartilages. ${ }^{1}$ The etiology is ambiguous, with both genetic and external factors implicated. ${ }^{2,3}$

PEX can also result in hemodynamic compromise, attributed to several mechanisms such as arrhythmias, right heart compression, and diminished lung capacity. ${ }^{4,5}$ A recent meta-analysis alluded to improved cardiorespiratory performance postsurgical correction. ${ }^{4}$

We describe a patient status post remote PEX repair who presented with exertional presyncope attributed to bifascicular block, partial right ventricular outflow tract (RVOT) obstruction, and right coronary artery (RCA) ischemia.

\section{Case Report}

A thirty-six-year-old biracial male (South-Asian, Caribbean-Black) with a medical history of PEX status post unknown type of repair twenty-two years ago presented to the emergency department with exertional presyncope during ballroom dancing. He had no significant social or family history and was not on any prescribed medication. His vital signs indicated systolic blood pressures of $116 \mathrm{~mm} \mathrm{Hg}$ with no orthostasis, heart rate of 97 beats/min, respiratory rate of 16 breaths/min with an oxygen saturation of $99 \%$ on ambient room air. His physical examination revealed a prominent anterior chest wall deformity with bilateral thoracotomy scars with an otherwise normal cardiorespiratory exam (Figure 1).

A 12-lead electrocardiogram (ECG) revealed sinus rhythm with left atrial enlargement (LAE), right bundle branch block (RBBB), and left anterior fascicular block (LAFB) (Figure 2). A chest radiograph displayed an obscured right heart border with an inferomedial "haziness" and narrow cardiac silhouette (Figure 3). A bedside two-dimensional transthoracic echocardiogram 


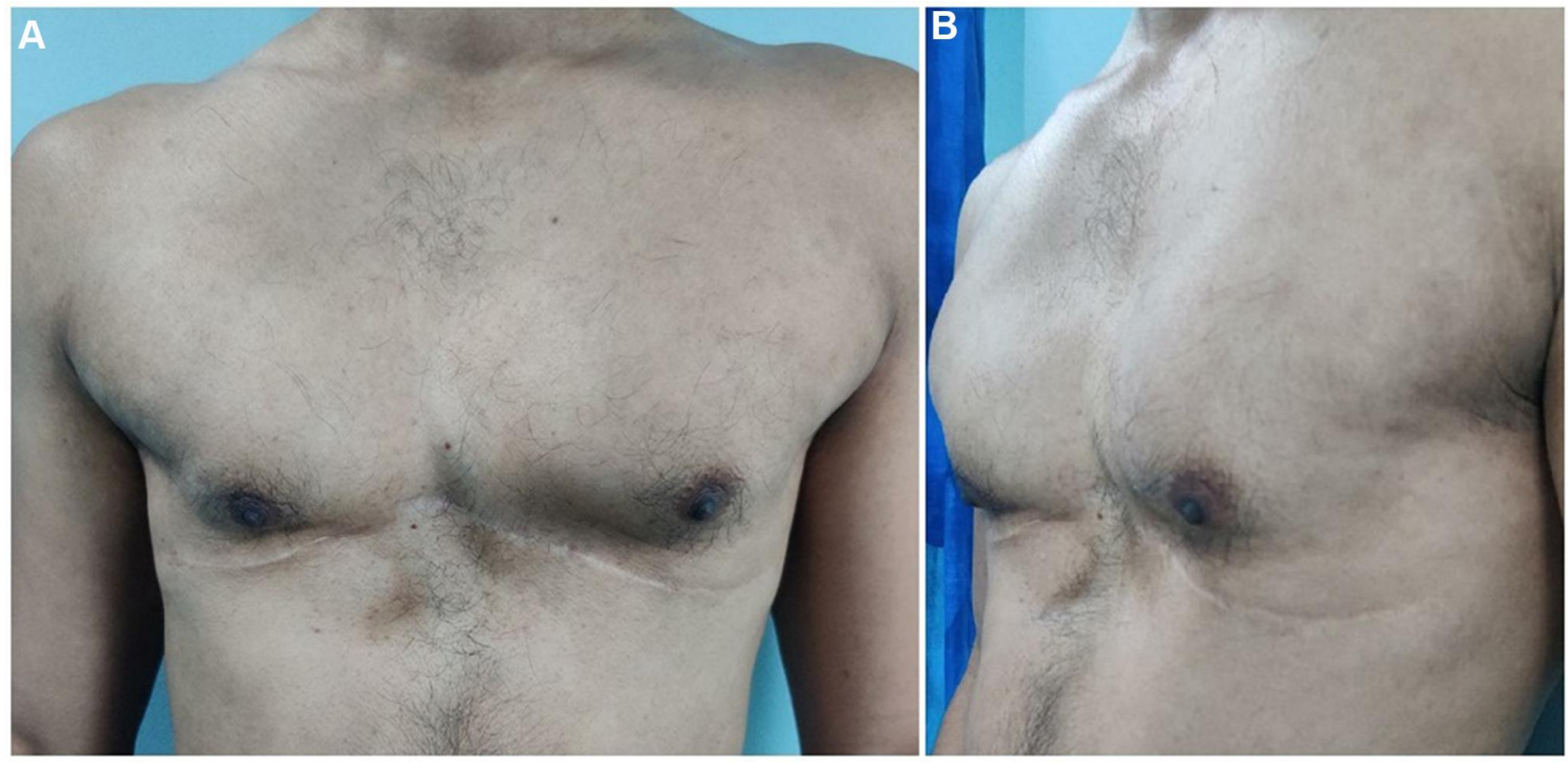

Figure I Status post remote pectus excavatum (PEX) repair twenty-two years ago. Notes: (A) Full front aspect of PEX repair. (B) Oblique visualization of PEX repair.

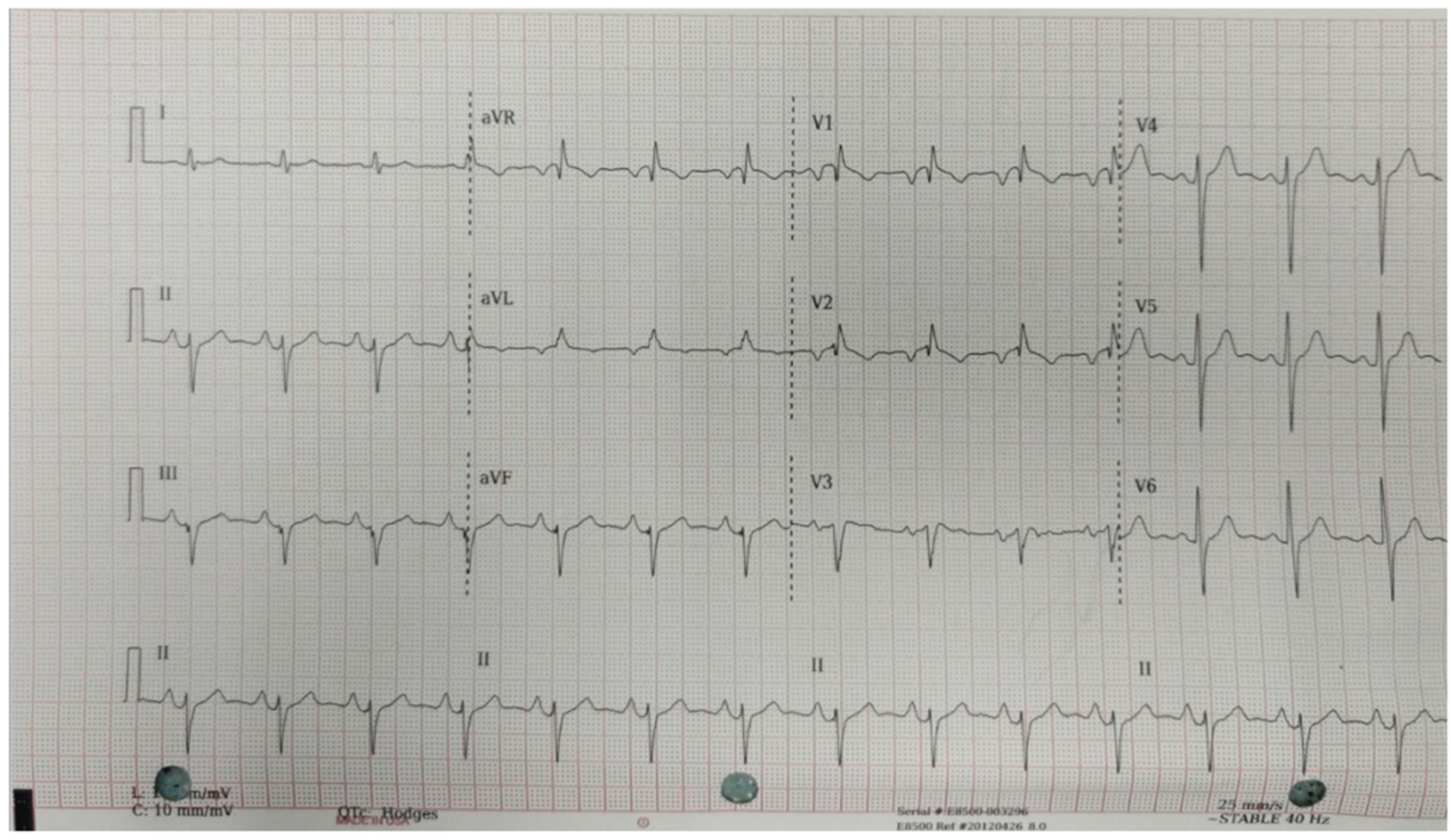

Figure 2 The patient's 12-lead electrocardiogram (ECG) displaying sinus rhythm with right bundle branch block (RBBB) and left anterior fascicular block (LAFB).

demonstrated normal left and right ventricular function with no evidence of mitral valve prolapse. Pertinent diagnostic laboratory investigations included a d-dimer 113 $\mathrm{ng} / \mathrm{dL} \quad$ (normal $\leq 500 \mathrm{ng} / \mathrm{mL}$ ), N-terminal-pro-brain natriuretic peptide $57 \mathrm{pg} / \mathrm{mL}$ (normal $\leq 300 \mathrm{pg} / \mathrm{mL}$ ), CKMB $8 \mathrm{U} / \mathrm{L}$ (normal $<20 \mathrm{U} / \mathrm{L}$ ), troponin I $0.01 \mathrm{ng} / \mathrm{mL}$ (normal $<0.15 \mathrm{ng} / \mathrm{mL}$ ), all of which were within respective normal ranges. SARS-CoV-2 IgM and IgM antibody 

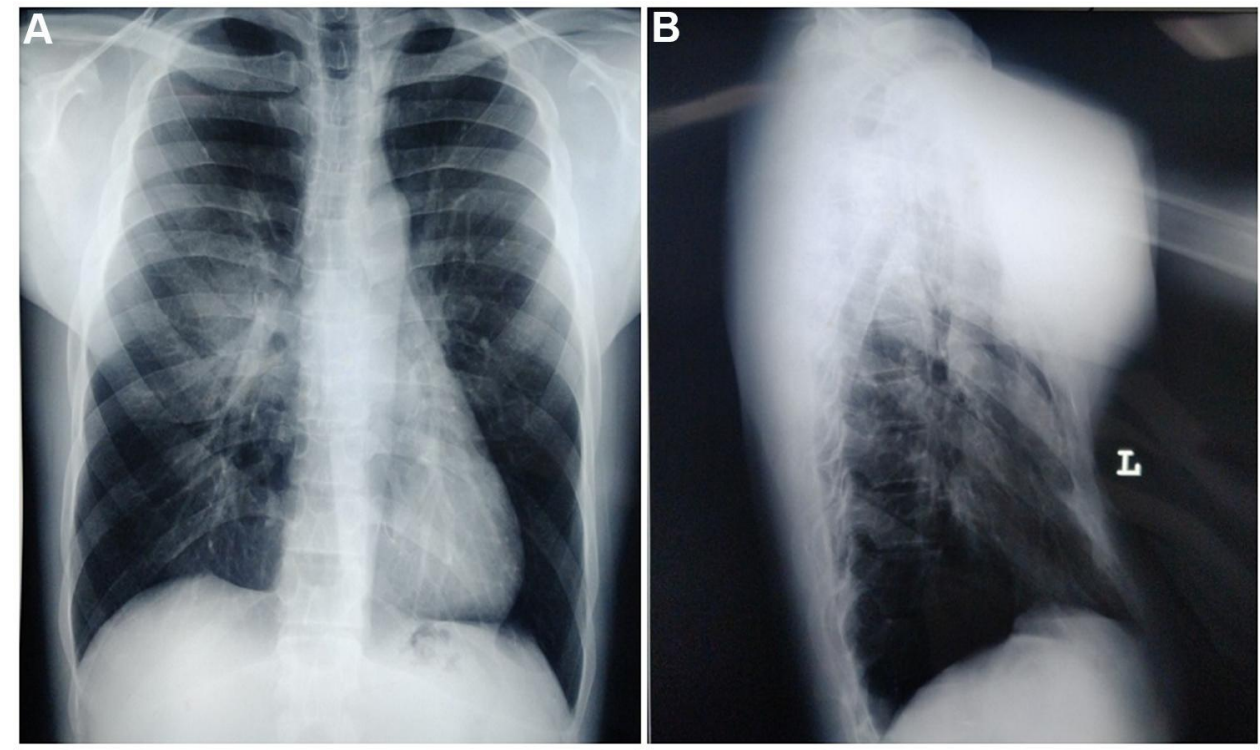

Figure 3 The patient's chest radiography.

Notes: (A) Posterior-anterior (PA) view indicating the relatively narrow cardiac silhouette and right hilar "haziness" mimicking either pulmonary edema or pneumonia. (B) Lateral view indicating the proximity of the right ventricular aspect of the heart to the sternum.

serologies (Abbott Laboratories, Chicago, Illinois, USA) were negative. A cardiac computed tomography angiogram (cCTA) revealed marked right ventricular (RV) free wall (Figure 4A) and infundibular outflow tract impingement (Figure 4B) with a Haller index of 5.2 (Figure 5) and ostial RCA compression or vasospasm (Figure 6).
He was subsequently admitted for further observation, where he underwent inpatient cardiac monitoring with a 48-hour Holter monitor, which did not indicate any second-degree or third-degree heart block. Cardiac magnetic resonance imaging (cMRI) was precluded in the setting of pre-existing sternal wires. He underwent an
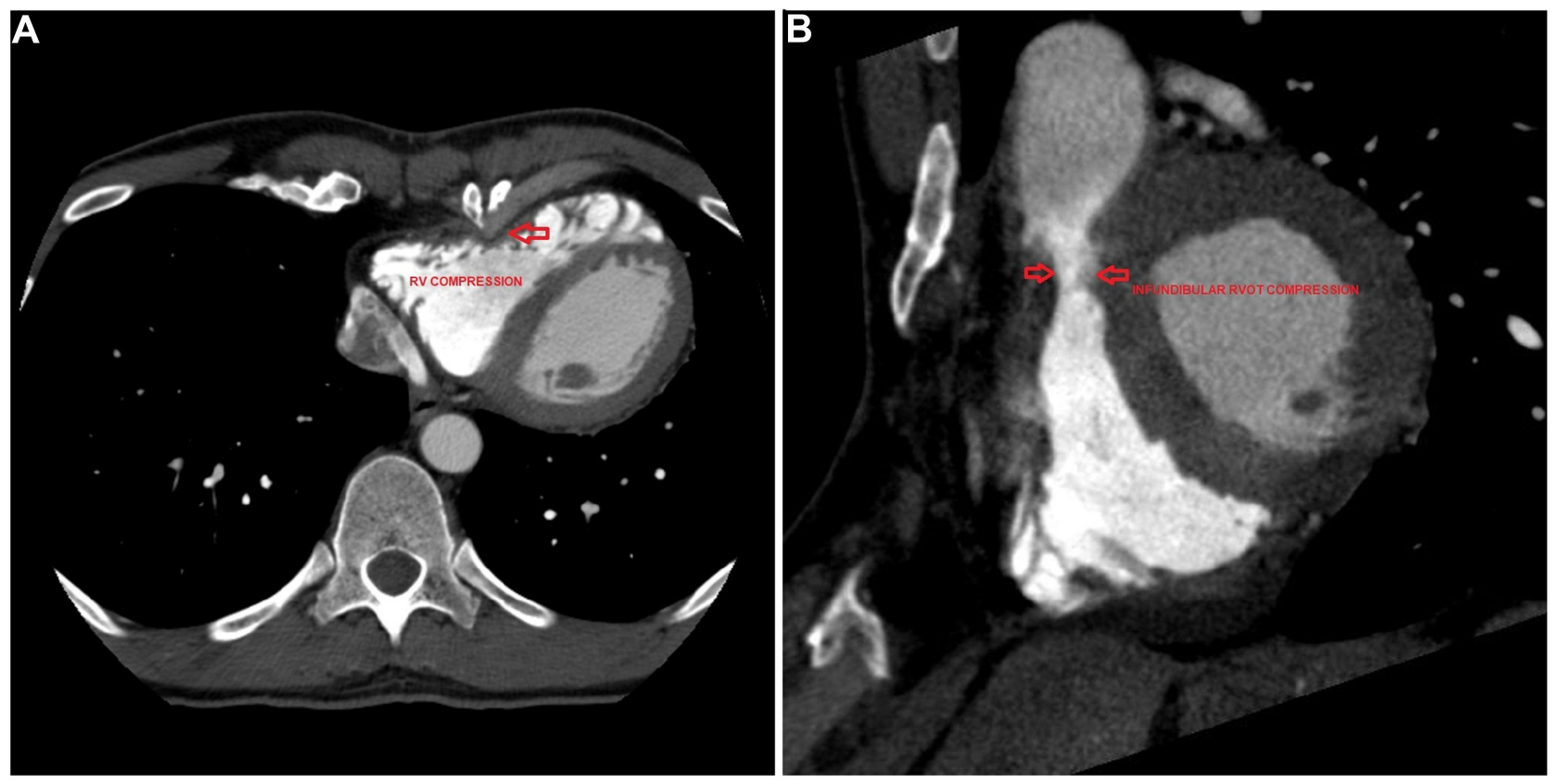

Figure 4 The patient's cardiac computed tomography angiogram (cCTA).

Notes: (A) Axial view of the sternum impinging on the right ventricular free wall demarcated by the red arrow. (B) Axial view of the sternum impinging on the right infundibular outflow tract demarcated by the red arrow. 


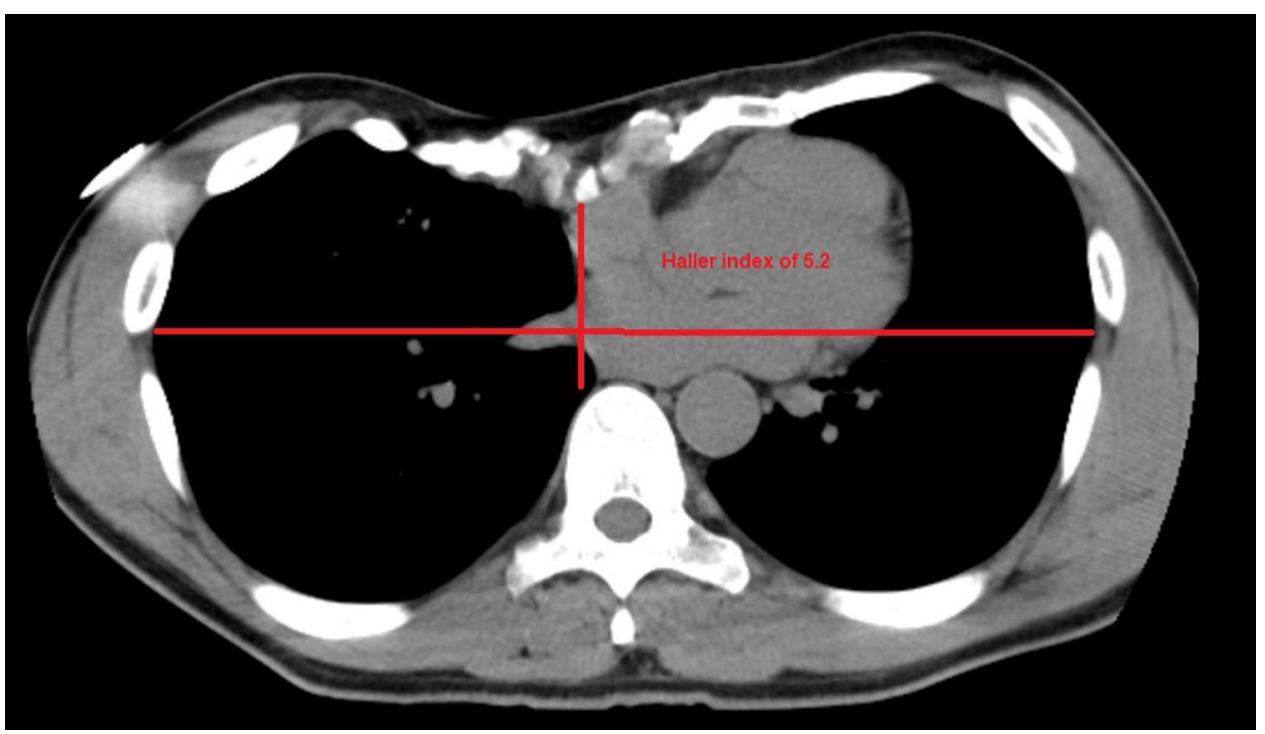

Figure 5 The patient's cardiac computed tomography angiogram (cCTA) demonstrating a relatively severe Haller index of 5.2 indicated by the ratio of the transverse diameter (the horizontal distance of the inside of the rib cage) and the anteroposterior diameter (the shortest distance between the vertebrae and sternum).

exercise stress echocardiogram for functional assessment in which he performed approximately 8 minutes (terminated due to fatigue) on the Bruce protocol with ten metabolic equivalents and overall was negative for ischemia on imaging criteria despite the bifascicular block. Pulmonary function testing indicated a borderline mild restrictive defect. On further questioning, the patient later revealed that he experienced occasional episodes (2-3) during the preceding years (3-4) during similar levels of exertion (ballroom dancing). He was offered cardiac catheterization and cardiothoracic surgery consultation for re-do sternotomy to alleviate structural issues and potential revascularization; however, he declined. The remainder of his two-day hospital course was uneventful, and he was subsequently discharged with sequential follow-up visits both one week and one month later, where he did not report any recurrent symptoms.

\section{Discussion}

Our patient's presentation is interesting in several aspects, such as the novel finding of a bifascicular block post repair. Firstly, our patient could not recall what PE surgical repair (Nuss or Ravitch techniques) he underwent 22 years ago, nor were there available documented medical records detailing such. Patients with severe PEX can have tachycardia due to a reduced stroke volume, depending on the distortion and displacement of the heart. ${ }^{6}$ The ECG may demonstrate right axis deviation and ST-segment depression, reflecting rotation and compression of the heart. Some patients have conduction abnormalities, such as bundle branch block and Brugada phenocopy. ${ }^{7-9}$ A negative portion of the $p$ wave in $V_{1}$ (not LAE) and complete or incomplete RBBB are associated with anatomical severity as indicated by the Haller index (the ratio of the transverse diameter [the horizontal distance of the inside of the rib cage] and the anteroposterior diameter [the shortest distance between the vertebrae and sternum]). ${ }^{10,11}$ Our patient displayed nearly all of these electrocardiographic features with the novel exception of a bifascicular block, which has not been described before.

We speculate that the left anterior fascicular block (LAFB) may have been artifactual with respect to his index surgical procedure two decades ago, similar to what has been described by Gräfe et al in 2011, in addition to the right bundle branch block with secondary ST-T changes. The reason for these ECG changes remains unclear but theorized to be related to electromagnetic interference from sternal bars or wires or malrotation of the cardiac axis within the thorax. LAFB is typically considered a benign ECG finding; however, its long-term sequelae has not been extensively prognosticated. Conduction blocks may occur due to conduction system fibrosis and possibly allude to left heart fibrosis, a substrate for atrial fibrillation and chronic heart failure. ${ }^{12,13}$ Progression of chronic bifascicular block to complete heart block appears to be infrequent among asymptomatic patients; however, among patients with syncope, the likelihood of progression to symptomatic high-grade heart block appears high. ${ }^{14,15}$ 


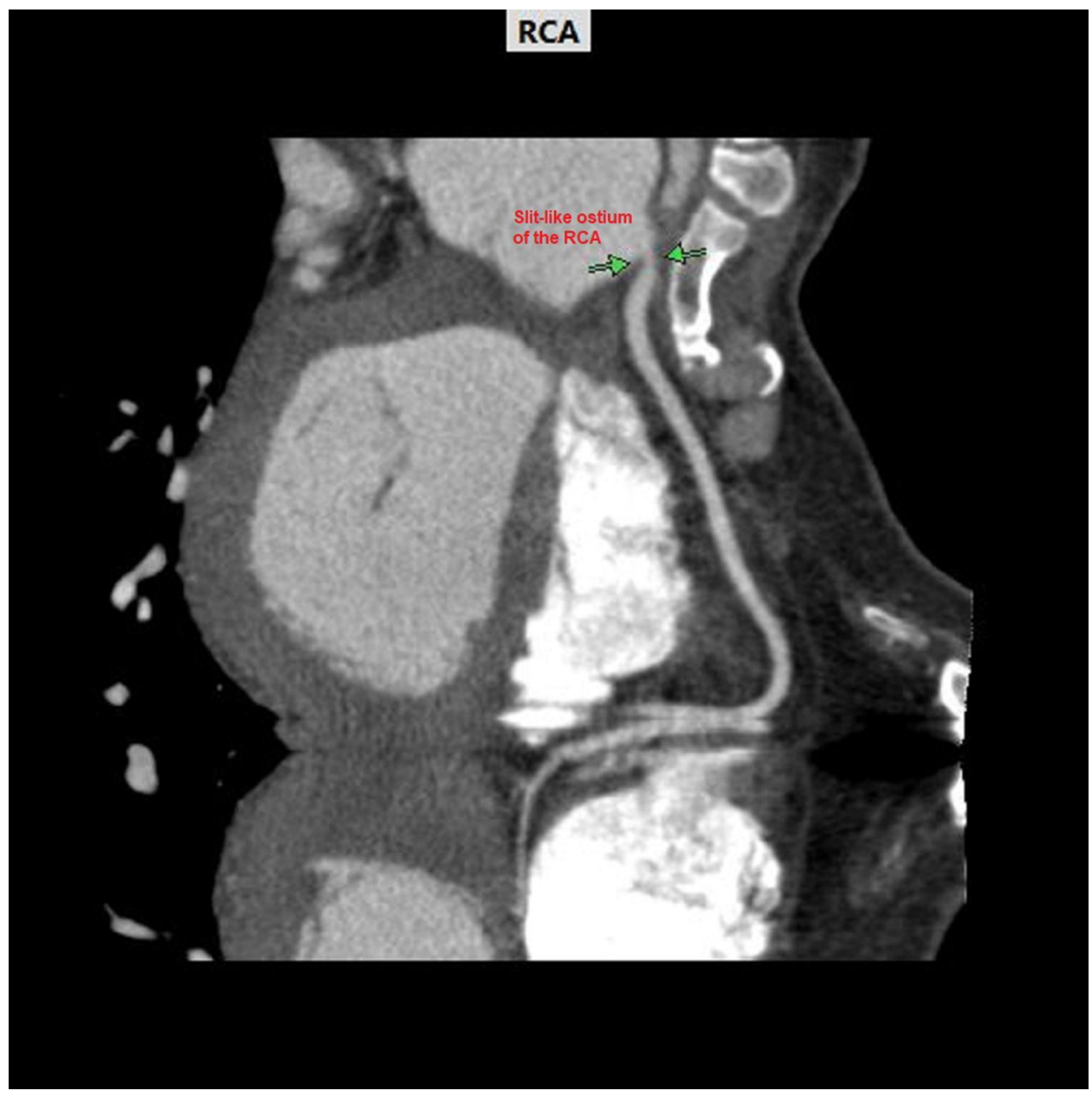

Figure 6 The patient's cardiac computed tomography angiogram (cCTA) demonstrates the slit-like ostial right coronary artery compression or vasospasm between the green arrows.

Briefly, PEX is an anterior chest wall deformity characterized by sternal depression, usually from the midportion of the manubrium with intrusion towards the xiphoid process. The etiology is not well ascertained, and several postulated hypotheses include disproportionate muscular forces, defective cartilage structure and growth, and abnormal rib growth. ${ }^{16}$ It accounts for approximately $90 \%$ of anterior chest wall disorders, with an estimated incidence of 1 in 400-1000 persons. ${ }^{17}$ It typically displays a male preponderance ( $3 \mathrm{x}-5 \mathrm{x}$ compared to women), usually sporadic in etiology, and is occasionally associated with some neuromuscular, connective tissue, and genetic disorders. ${ }^{18}$ The most common symptomatology displayed by patients is exercise intolerance, chest pain, and shortness of breath of approximately $80 \%, 70 \%$, and $40 \%$, respectively. ${ }^{19}$ Syncope is relatively uncommon at $10 \%{ }^{20,21}$
Additionally, this patient had severe PEX, despite an attempted correction with both RV free wall and infundibular outflow tract compression. This may have potentiated the patient's exertional presyncope. Both external and internal RV impingement likely led to the patient's exercise-induced presyncope, attributed to decreased filling times and stroke volumes. ${ }^{20}$ PEX is also associated with alteration in RV morphology and function due to compression of the heart between the vertebral column and the depressed sternum. The right ventricle is less concentric, with a comparatively anterior position and more distensible than the left ventricle. PEX can produce global RV dysfunction, irrespective of the rounded apex. RV dysplasia, sacculations of the free wall, and hypertrophy of the moderator band were more common in patients with pectus excavatum. ${ }^{22}$ Ostial RCA compression, mechanical displacement by sternal inversion or vasospasm could also precipitate transient presyncope. ${ }^{23,24}$ We postulate 
that the presyncope may have also been mediated by transient ischemia which could result in cardiac failure, tachyarrhythmia, and bradycardia, including sinus arrest and atrioventricular block. ${ }^{25,26}$

We speculate that the patient may have undergone a modified pediatric Ravitch procedure (the patient's age of index procedure was 14-years-old) based on his thoracotomy scars. A recent systematic review suggested there were no overt differences in outcomes between the Nuss and Ravitch populations across all age groups, however, alluded to marginally improved outcomes with the Nuss procedure when compared to other procedural subgroups such as duration of procedure and hospitalization, blood loss, complication rates including re-do operations, symptoms including cardiopulmonary function. ${ }^{27}$

Patients with PE should undergo routine surveillance with serial clinical examinations, complementary advanced imaging (cCTA and cMRI), stress testing techniques, and pulmonary function testing as they may identify higher-risk subpopulations for cardiorespiratory compromise. ${ }^{28}$

\section{Conclusion}

We describe a patient status post remote PEX repair who presented with presyncope attributed to bifascicular block, partial right ventricular outflow tract (RVOT) obstruction, and right coronary artery (RCA) ischemia. The clinician should be aware of these potential mechanisms precipitating presyncope.

\section{Abbreviations}

PEX, pectus excavatum; RVOT, right ventricular outflow tract obstruction, RCA, right coronary artery; ECG, electrocardiogram; LAE, left atrial enlargement, RBBB, right bundle branch block; LAFB, left anterior fascicular block; RV, right ventricular; cCTA, cardiac computed tomography angiogram; cMRI, cardiac magnetic resonance imaging.

\section{Data Sharing Statement}

All available data can be obtained by contacting the corresponding author.

\section{Compliance with Ethics Guidelines and Standards}

All procedures performed in studies involving human participants were in accordance with the ethical standards of the institutional and national research committee and with the 1964 Helsinki declaration and its later amendments or comparable ethical standards.

\section{Informed Consent}

The patient has provided verbal and written informed consent to have the details of his case, including images published. Institutional approval was not required for publication.

\section{Author Contributions}

All authors made substantial contributions to conception and design, acquisition of data, or analysis and interpretation of data; took part in drafting the article or revising it critically for important intellectual content; agreed to submit to the current journal; gave final approval of the version to be published; and agree to be accountable for all aspects of the work.

\section{Funding}

There is no funding to report.

\section{Disclosure}

The authors declare they have no competing interests, and there are no financial disclosures.

\section{References}

1. Dean C, Etienne D, Hindson D, Matusz P, Shane Tubbs R, Loukas M. Pectus excavatum (funnel chest): a historical and current prospective. Surg Radiol Anat. 2012;34:573-579. doi:10.1007/s00276-012-0938-7

2. Creswick HA, Stacey MW, Kelly RE, et al. Family study of the inheritance of pectus excavatum. $J$ Pediatr Surg. 2006;41:1699-1703. doi:10.1016/j.jpedsurg.2006.05.071

3. Shamberger RC. Congenital chest wall deformities. Curr Probl Surg. 1996;33:469-542. doi:10.1016/S0011-3840(96)80005-0

4. Maagaard M, Heiberg J. Improved cardiac function and exercise capacity following correction of pectus excavatum: a review of current literature. Ann Cardiothorac Surg. 2016;5:485-492. doi:10.21037/acs.2016.09.03

5. Kelly RE, Obermeyer RJ, Nuss D. Diminished pulmonary function in pectus excavatum: from denying the problem to finding the mechanism. Ann Cardiothorac Surg. 2016;5:466-475. doi:10.21037/ acs.2016.09.09

6. Saxena AK, Willital GH. Valuable lessons from two decades of pectus repair with the Willital-Hegemann procedure. $J$ Thorac Cardiovasc Surg. 2007;134:871-876. doi:10.1016/j.jtcvs.2007.06.008

7. de Oliveira JM, Sambhi MP, Zimmerman HA. The electrocardiogram in pectus excavatum. Heart. 1958;20:495-501. doi:10.1136/hrt.20.4.495

8. Gräfe D, Fitze G, Heilmann A. Incomplete left bundle branch block as an artefact caused by the Nuss procedure for pectus excavatum. Europace. 2011;13:258-261. doi:10.1093/europace/euq425

9. Awad SFM, Barbosa-Barros R, de Sousa Belem L, et al. Brugada phenocopy in a patient with pectus excavatum: systematic review of the ECG manifestations associated with pectus excavatum. Ann Noninvasive Electrocardiol. 2013;18:415-420. doi:10.1111/anec.12082

10. Haller JA, Alex haller J, Kramer SS, Lietman SA. Use of CT scans in selection of patients for pectus excavatum surgery: a preliminary report. J Pediatr Surg. 1987;22:904-906. doi:10.1016/s0022$3468(87) 80585-7$ 
11. Funabashi N, Koyama G, Kobayashi Y. Electrocardiogram finding in patients with pectus excavatum: relationship with anatomical severity indicated by the Haller index and acquired by computed tomography. J Am Coll Cardiol. 2019;463. doi:10.1016/s0735-1097(19)31071-x

12. Mandyam MC, Soliman EZ, Heckbert SR, Vittinghoff E, Marcus GM. Long-term outcomes of left anterior fascicular block in the absence of overt cardiovascular disease. JAMA. 2013;309:1587-1588. doi:10.1001/jama.2013.2729

13. Nielsen JB, Strandberg SE, Pietersen A, Graff C, Holst AG; Copenhagen ECG Study. Left anterior fascicular block and the risk of cardiovascular outcomes. JAMA Intern Med. 2014;174:1001-1003. doi:10.1001/ jamainternmed.2014.578

14. McAnulty JH, Rahimtoola SH, Murphy E, et al. Natural history of "highrisk" bundle-branch block: final report of a prospective study. $N$ Engl J Med. 1982;307:137-143. doi:10.1056/NEJM198207153070301

15. Martí-Almor J, Cladellas M, Bazán V, et al. [Novel predictors of progression of atrioventricular block in patients with chronic bifascicular block]. Rev Esp Cardiol. 2010;63:400-408. [Spanish]. doi:10.1016/S0300-8932(10)70060-9

16. Park $\mathrm{CH}$, Kim TH, Haam SJ, Lee S. Rib overgrowth may be a contributing factor for pectus excavatum: evaluation of prepubertal patients younger than 10 years old. $J$ Pediatr Surg. 2015;50:1945-1948. doi:10.1016/j.jpedsurg.2015.07.010

17. Fokin AA, Steuerwald NM, Ahrens WA, Allen KE. Anatomical, histologic, and genetic characteristics of congenital chest wall deformities. Semin Thorac Cardiovasc Surg. 2009;21:44-57. doi:10.1053/j.semtcvs.2009.03.001

18. Fonkalsrud EW. 912 open pectus excavatum repairs: changing trends, lessons learned: one surgeon's experience. World J Surg. 2009;33:180-190. doi:10.1007/s00268-008-9793-4

19. Bay V, Farthmann E, Naegele U. Unoperated funnel chest in middle and advances age: evaluation of indications for operation. $J$ Pediatr Surg. 1970;5:606-609. doi:10.1016/S0022-3468(70)80004-5
20. Borrhomée S, Lenoir M, Gouton M, Fadel E. Syncope caused by right ventricular obstruction by pectus excavatum. $J$ Thorac Cardiovasc Surg. 2016;151:e67-9. doi:10.1016/j.jtcvs.2015.10.018

21. White JA, Fine NM, Shargall Y. Images in cardiovascular medicine. Pectus excavatum with compression of the inferior vena cava: a rare cause of recurrent syncope. Circulation. 2009;120:1722-1724. doi:10.1161/CIRCULATIONAHA.109.866400

22. Park SY, Park TH, Kim JH, et al. A case of right ventricular dysfunction caused by pectus excavatum. J Cardiovasc Ultrasound. 2010;18:62-65. doi:10.4250/jcu.2010.18.2.62

23. Moffat AD, Al-Khatib JT, Michael J, Nguyen VX. Transient presyncope secondary to posterior descending artery occlusion. Case Rep Cardiol. 2011;2011:792938. doi:10.1155/2011/792938

24. Baumann S, Spearman JV, Schoepf UJ, Renker M. Pectus excavatum as an unexpected cause for typical cardiologic signs revealed at imaging. Eur Heart $J$ Cardiovasc Imaging. 2014;15:1184. doi:10.1093/ehjci/jeu102

25. Nishizaki M. Life-threatening arrhythmias leading to syncope in patients with vasospastic angina. J Arrhythm. 2017;33:553-561. doi:10.1016/j.joa.2017.04.006

26. Angelini P, Villason S, Chan AV, et al. Coronary Artery Anomalies: A Comprehensive Approach. Baltimore: Lippincott Williams \& Wilkins; 1999

27. Johnson WR, Fedor D, Singhal S. Systematic review of surgical treatment techniques for adult and pediatric patients with pectus excavatum. J Cardiothorac Surg. 2014;9:25. doi:10.1186/17498090-9-25

28. Mocchegiani R, Badano L, Lestuzzi C, Nicolosi GL, Zanuttini D. Relation of right ventricular morphology and function in pectus excavatum to the severity of the chest wall deformity. Am J Cardiol. 1995;76:941-946. doi:10.1016/S0002-9149(99)80266-5

\section{Publish your work in this journal}

The International Medical Case Reports Journal is an international, peer-reviewed open-access journal publishing original case reports from all medical specialties. Previously unpublished medical posters are also accepted relating to any area of clinical or preclinical science. Submissions should not normally exceed 2,000 words or 4 published pages including figures, diagrams and references. The manuscript management system is completely online and includes a very quick and fair peer-review system, which is all easy to use. Visit http://www.dovepress.com/testimonials.php to read real quotes from published authors. 